\title{
MODELLING STRUCTURAL BREAKS \\ IN THE US, UK AND JAPANESE UNEMPLOYMENT RATES
}

\author{
Guglielmo Maria Caporale \\ Brunel University, London
}

\author{
Luis A. Gil-Alana* \\ University of Navarra
}

\section{April 2006}

\begin{abstract}
In this paper we use a general procedure to detect structural breaks at unknown points in time which allows for different orders of integration and deterministic components in each subsample (see Gil-Alana, 2006). First, we extend it to the non-linear case, and show by means of Monte Carlo experiments that the procedure performs well in a non-linear environment. Second, we apply it to test for breaks in the unemployment rate in the US, the UK and Japan. Our results shed some light on the empirical relevance of alternative unemployment theories for these countries. Specifically, a structuralist interpretation appears more appropriate for the US and Japan, whilst a hysteresis model accounts better for the UK experience (and also for the Japanese one in the second subsanple). We interpret these findings in terms of different labour market features.
\end{abstract}

Keywords: Unemployment, Structural Breaks, Fractional Integration.

JEL Classification: C32, E32

Corresponding author: Professor Guglielmo Maria Caporale, Brunel Business School, Brunel University, Uxbridge, Middlesex UB8 3PH, UK. Tel.: +44 (0)1895 266713. Fax: +44 (0)1895 269770. E-mail: Guglielmo-Maria.Caporale@brunel.ac.uk

* The second author gratefully acknowledges financial support from the Ministerio de Ciencia y Tecnologia (SEC2005-07657, Spain). 


\section{Introduction}

In this paper we test for the existence of breaks at unknown points in time in the US, UK and Japanese unemployment rates by applying a procedure which is an extension of that introduced by Bai and Perron (1998). Our contribution is twofold. The first is of a methodological nature. As in Bai and Perron (1998), our approach is based on the least square principle. However, it is more general, since it allows for different (fractional) orders of integration as well as different deterministic trends in each subsample. Further, it allows for non-linear structures. Incorporating non-linearities into a fractional integration framework with breaks at unknown points in time has not been attempted before, and represents a methodological innovation. We investigate the properties of our test in the non-linear case by means of Monte Carlo simulation techniques. The second contribution is to provide useful empirical evidence to discriminate among different theories of unemployment. Note that under hysteresis (or persistence - see, e.g., Blanchard and Summers, 1986, 1987 and Cross, 1987)) the order of integration (denoted by d) should be equal to or close to 1 , whilst infrequent breaks would give support to the structuralist view (Phelps, 1994). On the other hand, a value of $d$ close to 0 would favour NAIRU theories (see, e.g., Friedman, 1968). We obtain empirical results using our method for testing for breaks, and interpret the findings in terms of differences in the structure of the labour markets of the countries we analyse.

The layout of the paper is as follows. Section 2 briefly reviews the recent empirical literature testing alternative theories of unemployment. Section 3 describes the econometric approach. Section 4 reports Monte Carlo evidence on the performance of our test in the non-linear case. Section 5 presents the empirical results. Section 6 summarises the main findings and offers some concluding remarks. 


\section{Testing unemployment theories: a brief review of the literature}

Alternative unemployment theories have different implications for the time series properties of unemployment. For instance, the natural rate theory (see Friedman, 1968, and Phelps, 1967, 1968) implies that the unemployment rate should fluctuate around a stationary equilibrium level (the natural rate, also known as NAIRU), which is determined by economic fundamentals. In "structuralist" models (see Phelps, 1994) the natural rate is "endogenised": as in NAIRU models, unemployment is viewed as having an equilibrium level to which it generally reverts when hit by shocks, but it is also thought to be subject to infrequent structural breaks, resulting from changes in economic fundamentals, which affect the equilibrium itself. Hence the unemployment series should be stationary provided one allows for breaks. However, the adequacy of both these theories to account for the behaviour of unemployment has been questioned in recent decades, owing to the observed high persistence of unemployment in Europe. Therefore, hysteresis models have been developed (see Blanchard and Summers, 1986, 1987, and Barro, 1998), which characterise unemployment as a pathdependent variable, with temporary shocks having permanent or highly persistent effects. The implication is that the unemployment rate should be a stochastic process with long memory, exhibiting a (near) unit root.

Several empirical papers have used time series and panel techniques to discriminate between the different unemployment theories. Initially, standard unit root tests (such as Augmented Dickey-Fuller (ADF, 1979) or Phillips-Perron, 1988) were carried out (see, e.g., Blanchard and Summers, 1986, and Alogoskoufis and Manning, 1988), the results generally being consistent with the hysteresis hypothesis. Gordon (1989) defined full hysteresis as the case of a unit root and persistence as AR stationarity, and did not find any evidence of full hysteresis in five countries (France, Germany, USA, Japan and the UK) for the time period 1873-1986. Graafland (1991) concluded that, in the 80s, the labour market in the Netherlands 
was characterised by a high and persistent level of unemployment. Lopez et al. (1996) reported that monthly unemployment in Spain (1976M6-1994M10) was consistent with hysteresis. Nott (1996) did not find evidence of hysteresis in Canada, while Wilkinson (1997) did. Subsequent studies allowed for structural breaks as well (see, e.g., Mitchell, 1993, Bianchi and Zoega, 1998, and Papell et al, 2000), using, for instance, the method developed by Zivot and Andrews (1992). The evidence presented in these papers mostly gave support to structuralist rather than hysteresis theories, as it suggested that unemployment can be adequately modelled as a stationary series with an infrequently changing equilibrium level.

In order to deal with the well-known problem of the low power of standard unit root tests (see Campbell and Perron, 1991 and DeJong, 1992), more recent studies have performed panel unit root tests. Again, some of these contributions do not address the issue of possible breaks - examples are the papers of Song and Wu (1998) and LeonLedesma (2002), where tests developed by Levin, Lin and Chu (2002, LLC hereafter) and Im, Pesaran and Shin (2003) respectively are implemented. In most cases, such studies conclude that hysteresis theories are most appropriate for the European experience, whilst NAIRU models appear to work better for the US. By contrast, other papers take into account the possibility of breaks in a panel context. Prominent examples are Murray and Papell (2000) and Strazicich, Tieslau and Lee (2001), applying to OECD data, respectively, the LLC test and a panel LM t-statistic with up to two level breaks introduced by Im, Lee and Tieslau (2005). Allowing for breaks is generally found to lead to a rejection of the hysteresis hypothesis, and to be consistent instead with structuralist explanations of the behaviour of unemployment. Various theoretical models have been put forward to endogenise the natural rate of unemployment. They rely alternatively on productivity growth (Pissarides, 1990), real interest rates (Blanchard, 1999), stock prices (Phelps, 1999), institutional variables (Nickell, 1998 and Nickell and Van Ours, 2000), or 
the interaction between institutional and macroeconomic variables (Blanchard and Wolfers, 2000).

Another recent strand of the literature has exploited new developments in econometrics to study unemployment persistence using fractionally integrated (ARFIMA) models (see, for instance, Tschernig and Zimmermann, 1992; Crato and Rothman, 1996; GilAlana, 2001a, 2002; etc.). This approach, unlike earlier ones focusing exclusively on integer degrees of differentiation, i.e., $\mathrm{d}=0$ (stationarity) and $\mathrm{d}=1$ (nonstationarity), has the advantage of allowing for fractional degrees of integration. The present study falls into the same category, and adopts a framework which enables us to investigate the relevance of the three types of unemployment theories mentioned above; since it allows for fractional orders of integration, it is appropriate for both stationary processes (NAIRU models), and highly persistent/nonstationary ones (hysteresis hypothesis), and by incorporating structural breaks it can also be used to model processes exhibiting regime change (structuralist theories). For instance, suppose that it is found that, as a result of including a break, the degree of persistence appears to be different in the two subsamples, i.e. under one regime shocks have persistent though not permanent effects on the unemployment rate, (i.e., $d<1$ ) whilst under the other those effects are permanent $(d \geq 1)$. This would indicate that the behaviour of unemployment is well captured by structural and hysteresis models respectively in the two subsamples, shedding light on their empirical relevance.

Non-linearities in the unemployment rate are also well documented. Specifically, unemployment has been found to rise faster in recessions than it falls during recoveries (see, e.g., Rothman, 1991 for the US case). Possible explanations are asymmetries in adjustment costs (Bentolilla and Bertoli, 1990), job destruction (Caballero and Hammour, 1994), and capital destruction (Bean, 1989). Such non-linearities have been modelled using Markov-switching models (see, e.g., Bianchi and Zoega), Smooth Transition 
AutoRegressive (STAR) models (see, e.g., Skalin and Teräsvirta, 2002), or a non-linear fractional integration framework (see Caporale and Gil-Alana, 2005). Given their possible importance, in the next section we extend the testing procedure for breaks used by GilAlana (2006) in order to allow for non-linear structures.

\section{The econometric approach}

In this section we present a procedure that enables us to examine the stationarity/nonstationarity nature of the series of interest in a very general framework. Firstly, instead of restricting ourselves to the standard I(0) (stationarity) or I(1) (nonstationarity) cases, we consider the possibility of fractional orders of integration. Assuming that a sequence $\left\{\mathrm{u}_{\mathrm{t}}, \mathrm{t}=0, \pm 1, \ldots\right\}$ is $\mathrm{I}(0)$, defined as a covariance stationary process with spectral density function that is positive and finite, we define an I(d) process as:

$$
(1-L)^{d} x_{t}=u_{t}, \quad t=1,2, \ldots
$$

where $d$ can be any real number. These processes were initially introduced by Robinson (1978), Granger $(1980,1981)$ and Hosking (1981), and they have been widely employed in recent years to describe the dynamic behaviour of economic and financial data. (Diebold and Rudebusch, 1989; Baillie, 1996; Gil-Alana and Robinson, 1997). Secondly, our framework also allows for the inclusion of deterministic terms, like intercepts, linear trends or even non-linear structures of the Threshold AutoRegressive (TAR) or Momentum Threshold AutoRegressive (MTAR)-form (see, e.g. Enders and Granger, 1998; Enders and Siklos, 2001). Finally, the possibility of structural breaks at unknown points in time is also taken into account.

Gil-Alana (2006) proposes a very simple procedure for estimating fractional orders of integration with deterministic linear trends and a single break at an unknown date. 
Following that approach, we assume that $y_{t}$ is the observed time series, generated by the model

$$
\begin{aligned}
& y_{t}=\alpha_{1}+\beta_{1} t+x_{t} ; \quad(1-L)^{d_{1}} x_{t}=u_{t}, \quad t=1, \ldots, T_{b} \\
& y_{t}=\alpha_{2}+\beta_{2} t+x_{t} ; \quad(1-L)^{d_{2}} x_{t}=u_{t}, \quad t=T_{b}+1, \ldots, T,
\end{aligned}
$$

where the $\alpha$ 's and the $\beta$ 's are the coefficients corresponding respectively to the intercept and the linear trend; $d_{1}$ and $d_{2}$ may be real values, $u_{t}$ is $I(0)$ and $T_{b}$ is the time of the break that is assumed to be unknown. Note that the model in equations (2) and (3) can also be written as:

$$
\begin{aligned}
& (1-L)^{d_{1}} y_{t}=\alpha_{1} \tilde{1}_{t}\left(d_{1}\right)+\beta_{1} \tilde{t}_{t}\left(d_{1}\right)+u_{t}, \quad t=1, \ldots, T_{b}, \\
& (1-L)^{d_{2}} y_{t}=\alpha_{2} \tilde{1}_{t}\left(d_{2}\right)+\beta_{2} \tilde{t}_{t}\left(d_{2}\right)+u_{t}, \quad t=T_{b}+1, \ldots, T,
\end{aligned}
$$

where $\widetilde{1}_{t}\left(d_{i}\right)=(1-L)^{d_{i}} 1$, and $\widetilde{t}_{t}\left(d_{i}\right)=(1-L)^{d_{i}} t, \mathrm{i}=1,2$.

This approach is based on the least square principle proposed by Bai and Perron (1998). First, we choose a grid for the values of the fractionally differencing parameters $d_{1}$ and $d_{2}$, for example, $d_{i o}=0,0.01,0.02, \ldots, 2, i=1,2$. Then, for a given partition $\left\{T_{b}\right\}$ and given $d_{1}, d_{2}$-values, $\left(d_{10}^{(j)}, d_{20}^{(j)}\right)$, we estimate the $\alpha$ 's and the $\beta$ 's by minimising the sum of squared residuals,

$$
\min \sum_{t=1}^{T b}\left[(1-L)^{d}{ }_{l o}^{(j)} y_{t}-\alpha_{1} \widetilde{1}_{t}\left(d_{l o}^{(j)}\right)-\beta_{1} \widetilde{t}_{t}\left(d_{1 o}^{(j)}\right)\right]^{2}+\sum_{t=T b+1}^{T}\left[(1-L)^{d}{ }^{(j o} y_{t}-\alpha_{2} \widetilde{1}_{t}\left(d_{2 o}^{(j)}\right)-\beta_{2} \widetilde{t}_{t}\left(d_{2 o}^{(j)}\right)\right]^{2}
$$
w.r.t. $\left\{\alpha_{1}, \alpha_{2}, \beta_{1}, \beta_{2}\right\}$

Let $\hat{\alpha}\left(T_{b} ; d_{1 o}^{(1)}, d_{2 o}^{(1)}\right)$ and $\hat{\beta}\left(T_{b} ; d_{1 o}^{(1)}, d_{2 o}^{(1)}\right)$ denote the resulting estimates for partition $\left\{\mathrm{T}_{\mathrm{b}}\right\}$ and initial values $d_{10}^{(1)}$ and $d_{2 o}^{(1)}$. Substituting these estimated values in the objective function, we obtain $\operatorname{RSS}\left(\mathrm{T}_{\mathrm{b}} ; d_{1 o}^{(1)}, d_{2 o}^{(1)}\right)$, and minimising this expression for all 
values of $d_{1 o}$ and $d_{2 o}$ in the grid we obtain:

$$
\operatorname{RSS}\left(\mathrm{T}_{\mathrm{b}}\right)=\arg \min _{\{\mathrm{i}, \mathrm{j}\}} \operatorname{RSS}\left(\mathrm{T}_{\mathrm{b}} ; \mathrm{d}_{1 \mathrm{o}}^{(\mathrm{i})}, \mathrm{d}_{2 \mathrm{o}}^{(\mathrm{j})}\right)
$$

Then, the estimated break date, $\hat{\mathrm{T}}_{\mathrm{k}}$, is such that

$$
\hat{T}_{k}=\arg \min { }_{i=1, \ldots, m} R S S\left(T_{i}\right),
$$

where the minimisation is over all partitions $T_{1}, T_{2}, \ldots, T_{m}$, such that $T_{i}-T_{i-1} \geq|\varepsilon T|$. The regression parameter estimates are the associated least-squares estimates of the estimated k-partition, i.e.,

$$
\begin{aligned}
& \hat{\alpha}_{i}=\hat{\alpha}_{i}\left(\left\{\hat{T}_{k}\right\}\right), \\
& \hat{\beta}_{i}=\hat{\beta}_{i}\left(\left\{\hat{T}_{k}\right\}\right),
\end{aligned}
$$

and their corresponding differencing parameters,

$$
\hat{d}_{i}=\hat{d}_{i}\left(\left\{\hat{T}_{k}\right\}\right)
$$

for $\mathrm{i}=1$ and 2 .

In Gil-Alana (2006) it is shown that the rates of convergence of the estimates are similar to those in Bai and Perron (1998), since the values are chosen in such a way as to minimise the residual sum of squares and, under the appropriate specification, $u_{t}$ should follow an I(0) process. Moreover, several Monte Carlo experiments conducted in that study show that the procedure performs extremely well even in relatively small samples.

In this paper we extend the above procedure to allow for non-linearities. That is, we consider for each subsample a model of the form

$$
y_{t}=f\left(z_{t} ; \theta\right)+x_{t}, \quad t=1,2, \ldots
$$

where $\mathrm{f}$ may be of a non-linear nature, $\mathrm{z}_{\mathrm{t}}$ is a vector of (weakly) exogenous variables, $\theta$ represents the unknown coefficients, and $x_{t}$ is driven by (1). The main problem with this equation lies in the interaction between the fractional polynomial $(1-L)^{d}$ and the possibly 
non-linear function $\mathrm{f}$, and the estimation of the parameters involved in such a relationship. For the purpose of the present study, let us assume that $f\left(z_{t} ; \theta\right)=\theta g\left(z_{t}\right)$, where $g$ is of a non-linear nature. In such a case, (1) and (6) become:

$$
(1-L)^{d} y_{t}=\theta^{\prime} w_{t}+u_{t}, \quad t=1,2, \ldots
$$

where $\mathrm{w}_{\mathrm{t}}=(1-\mathrm{L})^{\mathrm{d}} \mathrm{g}\left(\mathrm{z}_{\mathrm{t}}\right)$, and hence, the "non-linearity" is not in terms of the parameters, but in terms of a non-linear function of the variables $\mathrm{z}_{\mathrm{t}}$. We can obtain the OLS estimate of $\theta$ and residuals:

$$
\hat{u}_{t}=(1-L)^{d} y_{t}-\hat{\theta}^{\prime} w_{t}, \quad \hat{\theta}=\left(\sum_{t=1}^{T} w_{t} w_{t}{ }^{\prime}\right)^{-1} \sum_{t=1}^{T} w_{t}(1-L)^{d} y_{t},
$$

and the same type of analysis as in Gil-Alana (2006) can be conducted here. This procedure can easily be extended to the case of multiple breaks (see again Gil-Alana, 2006). In the present study, though, we do not consider this case, but focus instead on a single break to explain the stochastic nature of unemployment. The reason is the following. Structuralist theories imply infrequent breaks in the unemployment series. Therefore, there could be more than a single break. However, for the validity of the type of long-memory (fractional integration) model we use for unemployment it is necessary that the data span a sufficiently long period of time to detect the dependence across time of the observations; given the sample size of the series employed here, the inclusion of two or more breaks would result in relatively short subsamples, thereby invalidating the analysis based on fractional integration. Moreover, other recent empirical studies on unemployment in the US and UK come to the conclusion that a single break is sufficient to describe the behaviour of these series (e.g. Anderton, 1998).

\section{Monte Carlo results}

In this section we examine by means of Monte Carlo simulations the performance of the 
procedure described in Section 3 in the case of non-linear structures. We assume that the Data Generating Process (DGP) is the following:

$$
\begin{aligned}
& \mathrm{y}_{\mathrm{t}}=0.5 \mathrm{I}\left(\mathrm{y}_{\mathrm{t}-1}>0\right)+0.1 \mathrm{I}\left(\mathrm{y}_{\mathrm{t}-1} \leq 0\right)+\mathrm{x}_{\mathrm{t}} ; \quad(1-\mathrm{L})^{\mathrm{d}_{1}} \mathrm{x}_{\mathrm{t}}=\mathrm{u}_{\mathrm{t}}, \quad \mathrm{t}=1, \ldots, \mathrm{T}_{\mathrm{b}} \\
& \mathrm{y}_{\mathrm{t}}=1 \mathrm{I}\left(\mathrm{y}_{\mathrm{t}-1}>0\right)+0.5 \mathrm{I}\left(\mathrm{y}_{\mathrm{t}-1} \leq 0\right)+\mathrm{x}_{\mathrm{t}} ; \quad(1-\mathrm{L})^{\mathrm{d} 2} \mathrm{x}_{\mathrm{t}}=\mathrm{u}_{\mathrm{t}}, \quad \mathrm{t}=\mathrm{T}_{\mathrm{b}}+1, \ldots, \mathrm{T},
\end{aligned}
$$

where $\mathrm{I}(\mathrm{x})$ stands for the indicator function, and $\mathrm{u}_{\mathrm{t}}$ is a white noise process. We generate Gaussian series using the routines GASDEV and RAN3 of Press, Flannery, Teukolsky and Vetterling (1986).

\section{[Insert Figure 1 about here]}

Figure 1 contains plots of simple realisations of the model given by (8) and (9) with $\mathrm{T}=300, \mathrm{~T}_{\mathrm{b}}=150$, and $\left(\mathrm{d}_{1}, \mathrm{~d}_{2}\right)=(0,0),(0.25,0.25),(0.5,0.5),(0.25,0.75),(0.75$, $0.25)$ and $(1,1)$. It can be seen that, when the possibility of fractional integration is not considered (i.e., $d_{1}=d_{2}=0$ ), visual inspection of the series does not clearly reveal the occurrence of a structural break. By contrast, when $\mathrm{d}_{1}=\mathrm{d}_{2}=0.25$ or 0.5 , the break is clearly noticeable, and even more so for higher orders of integration (e.g., $d_{1}=d_{2}=1$ ). It can also be clearly detected when the orders of integration are different for each subsample.

Tables $1-3$ report the probabilities of correctly determining the timing of the break and the fractional differencing parameters in the model given by (8) and (9). In Table 1 it is assumed that in the true DGP, $T_{b}=T / 2, d_{1}=0.2$ and $d_{2}=0.4$. Thus, the two subsamples are covariance stationary, though with a component of long-memory behaviour. In Table $2, \mathrm{~T}_{\mathrm{b}}$ is still equal to $\mathrm{T} / 2, \mathrm{~d}_{1}=0.7$ and $\mathrm{d}_{2}=0.3$. Finally, in Table 3 , the break is assumed to take place at $T / 4$, with $\mathrm{d}_{1}=0.6$ and $\mathrm{d}_{2}=0.8$, and hence the two subsamples are now nonstationary. In all cases, we perform the procedure described in 
Section 3 for a grid of $d_{1}, d_{2}$ values $=0,0.2,0.4, \ldots, 2,{ }^{1}$ and values for the break $T^{*}=\left(T_{b}-\right.$ $T / 5),(1),\left(T_{b}+T / 5\right)$, where $T_{b}$ is the correct time of the break. The number of replication is equal to 10,000 in each case.

It is apparent from these tables that the adopted procedure determines accurately the break date in virtually all cases. We find zero-probabilities for all values of $d_{1}$ and $d_{2}$ if $T^{*}$ is smaller than $T_{b}-2$ or higher than $T_{b}+2$. Thus, we report in the tables only the probabilities corresponding to $\mathrm{T}^{*}=\mathrm{T}_{\mathrm{b}}-2, \mathrm{~T}_{\mathrm{b}}-1, \mathrm{~T}_{\mathrm{b}}, \mathrm{T}_{\mathrm{b}}+1$, and $\mathrm{T}_{\mathrm{b}}+2$.

In Tables 1 and 2 the break is assumed to take place at T/2. First, we consider the case of $d_{1}=0.2$ and $d_{2}=0.4$ (Table 1$)$. It can be seen that, if $T=100$, the procedure yields the correct specification of the model in $37.45 \%$ of the cases. The other two cases with a large percentage correspond both to $\mathrm{T}^{*}=\mathrm{T}_{\mathrm{b}}$, with $\mathrm{d}_{1}=\mathrm{d}_{2}=0.2(32.07 \%)$, and $\mathrm{d}_{1}=0.2$ and $\mathrm{d}_{2}=0.6(12.35 \%)$. For this sample size, the sum of the probabilities of correctly detecting the break-time is $93.19 \%$. Increasing the sample size appears to increase the probability of correctly specifying the model: this is equal to $57.91 \%$ with $\mathrm{T}=200 ; 70.15 \%$ with $\mathrm{T}=$ 300 , and $84.45 \%$ with $\mathrm{T}=500$. In this last case, the probability of accurately determining the break point is equal to $95.68 \%$.

\section{[Insert Tables 1 - 3 about here]}

In Table 2 we assume nonstationarity for the first subsample $\left(\mathrm{d}_{1}=0.7\right)$ and stationarity for the second one $\left(\mathrm{d}_{2}=0.3\right)$, still with a break at $\mathrm{T} / 2$. Here the highest probabilities are in all cases those corresponding to the true model, followed closely by those for the local departures $\left(\mathrm{d}_{1}=0.7\right.$ with $\mathrm{d}_{2}=0.1$ and 0.5$)$, with $\mathrm{T}^{*}=\mathrm{T} / 2$. In Table 3 it is assumed that the break takes place at $\mathrm{T} / 4$, and that the two subsamples are nonstationary $\left(d_{1}=0.6\right.$ and $\left.d_{2}=0.8\right)$. Here, the probabilities corresponding to the true model are slightly

\footnotetext{
${ }^{1}$ Of course, we could also have considered the case with $d_{1}, d_{2}$ equal to $0,0.1, \ldots, 1$, or even used a grid of 0.01 increments, but in such cases the probability of correctly determining the break would be substantially reduced by this refinement in the procedure, leading to higher probabilities for the parameter values close to the true one.
} 
smaller than in the previous cases, though still sufficiently high to detect the true DGP, especially if the sample size is large enough.

On the whole, the evidence presented in this section seems to suggest that our procedure for fractional integration with a structural break and non-linear structures performs well in finite samples.

\section{Empirical results}

All three unemployment rates are seasonally adjusted. The US series is quarterly, and covers the period 1960Q1-2004Q4; the source is the IMF's International Financial Statistics. The UK series is monthly, for the time period 1970M1 - 2005M9, and is obtained from the Labour Force Survey (http://www. statistics.gov.uk). In the case of Japan, the sample period is 1973Q1-2004Q2, and the data source is the OECD statistics. ${ }^{2}$

In Tables 4 - 6 we display the models selected on the basis of the procedure described in Section 3, for five different specifications. First, we consider the case without deterministic terms (model 1). Then, we assume a constant, and a constant and a linear trend, for each subsample (models 2 and 3); finally, we also consider non-linear TAR (model 4) and M-TAR (model 5) structures. More precisely, we estimate the following models:

1. $y_{t}=x_{t}, \quad(1-L)^{d_{i}} x_{t}=u_{t}, \quad t=T_{b_{i-1}}+1,2, \ldots, T_{b_{i}}$.

2. $y_{t}=\alpha_{i}+x_{t}, \quad(1-L)^{d_{i}} x_{t}=u_{t}, \quad t=T_{b_{i-1}}+1,2, \ldots, T_{b_{i}}$.

3. $y_{t}=\alpha_{i}+\beta_{i} t+x_{t}, \quad(1-L)^{d_{i}} x_{t}=u_{t}, \quad t=T_{b_{i-1}}+1,2, \ldots, T_{b_{i}}$.

4. $\quad y_{t}=\gamma_{1}^{i} I\left(\Delta y_{t-1}>0\right)+\gamma_{2}^{i} I\left(\Delta y_{t-1}<0\right)+x_{t},(1-L)^{d_{i}} x_{t}=u_{t}, t=T_{b_{i-1}}+1,2, \ldots, T$

\footnotetext{
${ }^{2}$ Note that higher data frequencies (with more observations) are preferable for the purpose of fractional integration analysis, but monthly data were available only in the case of the UK; therefore, quarterly series have been used for the US and Japan.
} 
5. $y_{t}=\delta_{1}^{i} I\left(y_{t-1}>\bar{y}\right)+\delta_{2}^{i} I\left(y_{t-1}<\bar{y}\right)+x_{t},(1-L)^{d_{i}} x_{t}=u_{t}, t=T_{b_{i-1}}+1,2, \ldots, T$,

where $\bar{y}$ in models 4 and 5 refers to the sample mean, and $\mathrm{T}_{\mathrm{b} 0}=1 ; \mathrm{T}_{\mathrm{b} 1}=\mathrm{T}_{\mathrm{b}}$ and $\mathrm{T}_{\mathrm{b} 2}=\mathrm{T}$. In each case we assume that the $\mathrm{I}(0)$ disturbances $\mathrm{u}_{\mathrm{t}}$ follow first a white noise and then an AR(1) process of form: $u_{t}=\alpha_{i} u_{t-1}+\varepsilon_{t}, i=1$, 2. Higher AR structures were also considered, and the results were not significantly different from those presented here.

\section{[Insert Table 4 about here]}

For the U.S. series, the main results are the following (see Table 4). The break date is almost the same in all models, ranging from $72 \mathrm{Q} 2$ to $75 \mathrm{Q} 1$ (it is $75 \mathrm{Q} 1$ in 4 out of the 10 models presented). It clearly corresponds to the first oil price shock. The values of $d_{1}$ and $d_{2}$ (the order of integration of the first and second subsample respectively) are in most cases between 0 and 1, providing evidence of fractional integration and persistence. The estimates of the parameter $d_{1}$ range between 0.66 and 1.01, and those of $d_{2}$ between 0.80 and 1.11. In general, we observe higher orders of integration in the second subsample, implying that the degree of persistence is higher after the break. The white noise and $A R(1)$ specifications yield rather similar results. When a linear time trend is included in the model (model 3), the slope coefficients are statistically insignificant in both subsamples. Therefore, model 3 can be discarded in favour of model 2 (with an intercept). As for the non-linear structures, the coefficients of model 4 are significant for the first subsample $\left(\gamma_{1}^{1}\right.$ and $\left.\gamma_{2}^{1}\right)$, while in model 5 they are significant for the second subsample only $\left(\delta_{1}^{2}\right.$ and $\left.\delta_{2}^{2}\right)$. The similarities between the coefficients of the non-linear models in the two subsamples seem to indicate that the adjustment process is symmetric in the case of US unemployment. Note, for example, that in model 4 the significant coefficients are 5.342 and 5.419 for the first subsample. In model 5, the values are 2.973 and 3.123 for the case of white noise $\mathrm{u}_{\mathrm{t}}$, and 11.485 and 11.501 with autocorrelated disturbances. 


\section{[Insert Table 5 about here]}

The results for U.K. are reported in Table 5. As can be seen, in most cases the break occurs in the early 80 s, namely a decade later than in the US (only in three of the estimated models there is an earlier break, more precisely in 1973). Further, unlike in the US case, virtually all the fractional parameters are estimated to be higher than 1, implying permanent deviations from equilibrium and a much higher degree of persistence in the UK unemployment rate. ${ }^{3}$ Specifically, the values of $d_{1}$ are found to range between 0.99 and 1.83, and those of $\mathrm{d}_{2}$ between 1.07 and 1.52. The range of values becomes narrower if the three cases corresponding to a break occurring in the 70 s are excluded, being now equal to [1.50 - 1.83] and [1.37 - 1.52] for $\mathrm{d}_{1}$ and $\mathrm{d}_{2}$ respectively. This is in line with previous papers on UK unemployment, finding orders of integration strictly above 1 (Gil-Alana, $2001 \mathrm{~b}, \mathrm{c})$. As in the US case, there is no evidence of asymmetries when estimating nonlinear TAR and M-TAR models. For example, in model 5, the significant coefficients in the two subsamples are $-3.386,4.031$ and $-3.406,4.024$, respectively in the case of white noise disturbances, and $-3.528,1.974$ and $-3.535,1.966$ with AR(1) disturbances.

\section{[Insert Table 6 about here]}

Table 6 reports the results for Japan. It can be seen that in this case all the estimated break points are between 1992Q2 and 1993Q2. In fact, in four out of the ten models considered, the break takes places in the first quarter in 1993, namely one decade later than in the UK, and almost two decades later than in the US. It can be argued that this might be a consequence of the sample period considered, which starts in 1973Q1. Therefore, as a robustness check, we also applied our procedure to annual data, which are available from 1960, and the break was again found to occur in $1993 .^{4}$ The orders of

\footnotetext{
${ }^{3}$ Anderton (1998) also finds persistence in the UK unemployment, though in his study the break occurs slightly earlier, namely in 1979.

${ }^{4}$ Anderton (1998) reports that a break took place in 1974, with an increase in unemployment persistence. Our results are more mixed.
} 
integration are clearly different in the two subsamples, before and after the break. Specifically, before 1993, most of the estimated values are strictly smaller than 1, while after that date they are equal to or higher than 1 . If $\mathrm{u}_{\mathrm{t}}$ follows an $\mathrm{AR}(1)$ process, the estimated values of $d_{1}$ are very close to 0 in three out of the five models, being equal to $0.04,0.03$ and 0.14 for model 2, 3, and 5 respectively. In these cases, however, it is clear that the low order of integration found in the first subsample is associated with large AR coefficients describing the time dependence across the observations, these coefficients being equal to $0.969,0.959$ and 0.925 for models 2,3 and 5 respectively.

Next, we select for each country the best model on statistical grounds. In the case of the US, a time trend appears not to be required, since the slope coefficients are not significantly different from zero. Moreover, the estimated coefficients for the two nonlinear models are rather similar in the two subsamples, and therefore these models can be ruled out. In the model with an intercept (model 2), the estimated order of integration is slightly above 1 in the second subsample for the case with AR(1) disturbances, and the AR coefficients are close to zero in the two subsamples. Therefore, the following specification is chosen for the US:

$$
\begin{gathered}
y_{t}=5.758+x_{t} ; \quad(1-L)^{0.68} x_{t}=\varepsilon_{t}, \quad t=1,2, \ldots, T_{b}=75 Q 1, \\
y_{t}=8.837+x_{t} ; \quad(1-L)^{0.83} x_{t}=\varepsilon_{t}, \quad t=T_{b}+1, \ldots, T .
\end{gathered}
$$

Moving on to the UK, again it appears that the non-linear models can be discarded because of the insignificant coefficients (in model 4) and the similarities between the coefficients in the two subsamples (in model 5). Model 3 can also be discarded on the grounds of the insignificance of the slope coefficients. Thus, we focus on model 2 (with an intercept): in both cases (white noise and $\operatorname{AR}(1) u_{t}$ ) the coefficients for the orders of integration are higher than 1 , and also higher in the first subsample. We choose the specification with autocorrelated disturbances because of the significant coefficients. 
Therefore, the selected model is the following:

$$
\begin{aligned}
& y_{t}=3.615+x_{t} ; \quad(1-L)^{1.82} x_{t}=u_{t} ; \quad u_{t}=-0.513 u_{t-1}+\varepsilon_{t}, \quad t=1,2, \ldots, T_{b}=81 M 4, \\
& y_{t}=9.236+x_{t} ; \quad(1-L)^{1.52} x_{t}=u_{t} ; \quad u_{t}=-0.271 u_{t-1}+\varepsilon_{t}, \quad t=T_{b}+1, \ldots, T .
\end{aligned}
$$

Finally, in the case of Japan, using the same type of arguments as before, we focus on the model with an intercept (model 2). When $\mathrm{u}_{\mathrm{t}}$ is specified as a white noise the orders of integration are 0.93 and 1.42 respectively for the two subsamples, whilst, if $u_{t}$ is modelled as an AR(1) process, the corresponding values are 0.04 and 1.42. (As previously mentioned, the low order of integration in case of the first subsample is due to the competition with the $\mathrm{AR}$ coefficient in describing the dependence across the observations). Thus, for this country we choose the following model:

$$
\begin{gathered}
y_{t}=1.271+x_{t} ; \quad(1-L)^{0.93} x_{t}=\varepsilon_{t}, \quad t=1,2, \ldots, T_{b}=93 Q 2, \\
y_{t}=2.392+x_{t} ; \quad(1-L)^{1.42} x_{t}=\varepsilon_{t}, \quad t=T_{b}+1, \ldots, T .
\end{gathered}
$$

\section{[Insert Figure 2 about here]}

Figure 2 shows the impulse responses to a unit shock computed for the first 25 periods for each country and each subsample, based on the selected models. It can be seen that in the US (and also in Japan in the second subsample) the size of the response increases at first and then starts decreasing very slowly. Also, in the US the convergence process is slower during the second subsample. By contrast, in the remaining cases (the two subsamples in UK and the second one in Japan) the process is explosive and not mean-reverting even in the long run, consistently with the earlier findings on persistence.

To sum up, the empirical results indicate that there is a single significant break occurring in all three cases (though the dating is different: the early 70 s in the UK, a decade later in the US, and two decades later in Japan). This could be seen as prima facie evidence that a structuralist model might be appropriate to describe unemployment 
behaviour in these countries. However, a closer look at the order of integration of the series suggests that this might not be the case for all three economies. Specifically, the fact that the estimated fractional parameters are consistently higher than 1 in the UK means that in this country the economic environment is such that shocks to unemployment (and hence macroeconomic policy) have permanent effects, thereby giving support to a hysteresis model. An order of integration higher than 1 is also found in the case of Japan in the second subsample, indicating a change in the labour market that has resulted in hysteresis. By contrast, in the first subsample, and in both periods in the case of the US, the estimated degree of persistence implies that, although the speed of adjustment towards equilibrium is slow, ${ }^{5}$ unemployment exhibits mean reversion, consistently with the natural rate hypothesis, appearing to be a near-unit root process, with shocks having long-lasting but not permanent effects. This finding, combined with the evidence of a break, gives support to a structuralist view of unemployment behaviour. Hence it appears that different models (hysteresis and structuralist) are appropriate to account for the unemployment experience of the different countries and periods under investigation. The impulse response analysis also confirms the earlier findings.

Overall, our results, and the persistence ranking, are in line with earlier studies (e.g., Alogoskoufis and Manning, 1988), also reporting that Japan and the US typically display lower degrees of unemployment persistence than European countries. The mixed evidence on whether persistence has decreased or increased in the UK since the early 1980s ${ }^{6}$ might at first seem surprising in view of the labour market reforms (aimed at eliminating rigidities) implemented by the Conservative government led at the time by Mrs. Thatcher. However, other authors, such as Blanchflower and Freeman (1994), have

\footnotetext{
${ }^{5}$ In Anderton (1998), the unemployment persistence parameter is estimated to be highest in the UK, and bigger in Japan than in the US, as in the present paper.

${ }^{6}$ We find that the estimated fractional parameters are higher in the first subsample for the selected model and in most, but not all cases. (See Table 5).
} 
reported a slower transition from unemployment to employment in the Thatcher years.

These results can be explained in terms of labour market and institutional differences. It is usually argued that the poorer unemployment performance of the European economies compared to the US is due to imperfections in the labour market (see, e.g., Layard et al, 1991). Features such as decentralised wage determination (see Calmfors and Driffill, 1988), low social security and trade union density, and minimum employment protection are often thought to account for the better labour market outcomes in the US. ${ }^{7}$ But in the period 1970-1990 Japan outperformed even the US in terms of unemployment. In the Layard et al. (1991) study, wage flexibility in the small business sector and the fact that female workers exit the labour market during recessions were highlighted as important factors accounting for the absence of hysteresis in Japan. An OECD study (1994) attributed instead the successful Japanese experience to some other key features of the Japanese labour market, in particular long-term employment relationships, high investment in training and worker loyalty. As for the higher degree of persistence since the early 90 s, this might be due to intensive on-the-job training and the resulting firmspecific skills leading to high costs of hiring and firing: in response to possibly temporary negative shocks, firms might be reluctant to fire employees with highly specialised skills, who would have to be replaced in the upturn by new workers requiring costly additional training. This reduces both job creation and destruction, and hence increases unemployment persistence. ${ }^{8}$

\footnotetext{
${ }^{7}$ Note, however, that the neoclassical paradigm (with the associated deregulation policies) has been criticised as exhibiting some theoretical weaknesses, such as second best problems, externalities etc. (see, e.g., Greg and Manning, 1997). Also, it has been pointed out that, in addition to the degree of centralisation, other features of the bargaining process, such as the degree of unionisation and coordination, as well as the coverage of bargaining, are important (see OECD, 1997).

${ }^{8}$ For a more extensive discussion of the Japanese case, see Brunello (1990).
} 


\section{Conclusions}

In this paper we have made a twofold contribution. First, we have extended to the nonlinear case a general procedure to detect structural breaks at unknown points in time which allows for different orders of integration and deterministic components in each subsample (see Gil-Alana, 2006). The suggested procedure has been shown by means of Monte Carlo experiments to be able to determine accurately the timing of the break in a non-linear, fractionally integrated framework. Second, we have applied it to test for breaks in the US, UK and Japanese unemployment rates, and assessed the empirical relevance of alternative unemployment theories in each case.

Our empirical findings suggest that unemployment is subject to infrequent breaks (more specifically, a single break has been identified in the three countries under study), and that non-linearities do not play a very important role. Moreover, unemployment appears to exhibit a higher degree of persistence in the UK compared to the US and Japan (although in the case of the US persistence has risen since the beginning of the $80 \mathrm{~s}$, and in Japan hysteresis is found in the period starting in 1993). Overall, it seems that a structuralist interpretation (see Phelps, 1994) is more appropriate for the US and Japan, whilst a hysteresis model (see Blanchard and Summers, 1986, 1987, and Barro, 1998) accounts better for the UK experience (and also for the Japanese one in the second subsample). The persistence ranking and the results in general can be interpreted in terms of the different characteristics of the labour market in the countries being analysed. In particular, imperfections and rigidities preventing or slowing down labour market adjustment and clearing (despite the Thatcher reforms) might be responsible for the inferior unemployment performance of the UK compared to the US and Japan. The better labour market outcomes achieved in the two latter countries could be attributed to higher flexibility and deregulation in the case of the US, whilst long-term employment 
relationships and other related factors might play a role in the case of Japan (see Layard et al, 1991).

Our analysis could be extended by estimating a multivariate fractional model, including regressors such as real oil prices and real interest rates, which might account for the observed behaviour of the unemployment rate, and also allowing for possible crosscountry linkages. This could be particularly informative when analysing the impulse response of unemployment to various types of shocks (e.g. price shocks), including shocks affecting unemployment in other countries in the first instance. However, this is beyond the scope of the present study, and is left for future research. 


\section{References}

Alogoskoufis, G.S. and A. Manning, 1988, "On the persistence of unemployment", Economic Policy, 7, 427-469.

Anderton, R., 1998, "Policy regimes and the persistence of wage inflation and unemployment", The Manchester School, 66, 418-438.

Bai, J. and J. Perron, 1998, "Estimating and testing linear models with multiple structural changes", Econometrica, 66, 47-78.

Baillie, R.T., 1996, "Long memory processes and fractional integration in econometrics", Journal of Econometrics, 73, 5-59.

Barro, R., 1988, "The natural rate theory reconsidered: the persistence of unemployment", American Economic Review, Papers and Proceedings, 78, 32-37.

Bean, C.R. (1989), “Capital shortage”, Economic Policy, 8, 11-53.

Bentolilla, S. and G. Bertola (1990), "Firing costs and labour demand: how bad is eurosclerosis?", Review of Economic Studies, 57, 381-402.

Bianchi, M. and G. Zoega, 1998, "Unemployment persistence: does the size of the shock matter?", Journal of Applied Econometrics, 13, 283-304.

Blanchard, O.J., 1999, "Wage dynamics: reconciling theory and evidence", American Economic Review, Papers and Proceedings, 89, 2, 69-74.

Blanchard, O.J. and L.H. Summers, 1986, "Hysteresis and the European unemployment problem", NBER Working Paper Series no. 1950.

Blanchard, O.J. and L.H. Summers, 1986, "Hysteresis in unemployment", European Economic Review, 31, 288-295.

Blanchard, O.J. and J. Wolfers, 2000, "The role of shocks and institutions in the rise of European unemployment: the aggregate evidence", Economic Journal, 110, C1-C33.

Blanchflower, D. and R. Freeman (1994), "Did the Thatcher reforms change British labour market performance?" in R. Barrell (ed.), The UK Labour Market, Cambridge, Cambridge University Press.

Brunello, G. (1990), "Hysteresis and "The Japanese Unemployment Problem": A Preliminary Investigation”, Oxford Economic Papers, 42, 3, 483-500.

Caballero, R.J. and M.L. Hammour (1994), "The cleansing effect of recessions", American Economic Review, 84, 1350-1368.

Calmfors, L. and J. Driffill (1988), "Bargaining structure, corporatism and macroeconomie performance", Economic Policy, 3, 6 (April 1988), 13-61. 
Campbell, J.Y. and P. Perron, 1991, "Pitfalls and opportunities: What macroeconomists should know about unit roots", NBER Macroeconomics Annual, 1141-201.

Caporale, G.M. and L.A. Gil-Alana (2005), "Non-linearities and fractional integration in the US unemployment rate", WP no. 05-17, Department of Economics and Finance, Brunel Business School, Brunel University, London; also, DP no. 05-13, Centre for International Capital Markets, London Metropolitan University, London.

Crato, N. and P. Rothman, 1996, Measuring hysteresis in unemployment rates with long memory models, Working Paper, East Carolina University, Department of Economics.

Cross, R., 1987, "Hysteresis and instability in the natural rate of unemployment", Scandinavian Journal of Economics, 89, 1, 71-89.

De Jong, D.N., J. Nankervis, N.E. Savin and C.H. Whiteman, 1992, "The power problems of unit root tests in time series with autoregressive errors", Journal of Econometrics, 53, 323-343.

Dickey, D. and W. Fuller, 1979, "Distribution of the estimators for autoregressive time series with a unit root", Journal of the American Statistical Association, 74, 427-431.

Diebold, F.X. and G.D. Rudebusch, 1989, "Long memory and persistence in aggregate output”, Journal of Monetary Economics, 24, 189-209.

Friedman, M., 1968, “The role of monetary policy", American Economic Review, 58, 117.

Enders, W. and C.W.J. Granger, 1998, "Unit-root tests abd asymmetric adjustment with an example using the term structure of interest rates", Journal of the American Statistical Association, 16, 3, 304-11.

Enders, W. and P. Siklos, 2001, "Cointegration and threshold adjustment", Journal of Business and Economic Statistics, 19, 2, 166-176.

Gil-Alana, L.A., 2001a, The persistence of unemployment in the USA and Europe in terms of Fractionally ARIMA Models, Applied Economics, 33 (10), 1263-1269.

Gil-Alana, L.A., 2001b, Estimation of fractional ARIMA models for the UK unemployment, Annales d'Economie et de Statistique, 62, 127-137.

Gil-Alana, L.A, 2001c, A fractionally integrated exponential spectral model for the UK unemployment, Journal of Forecasting, 20, 329-340.

Gil-Alana, L.A., 2002, Modelling the Persistence of Unemployment in Canada, International Review of Applied Economics, 16, 465-478.

Gil-Alana, L.A., 2006, Fractional integration and structural breaks at unknown periods of time, mimeo, University of Navarra.

Gil-Alana, L.A. and P.M. Robinson, 1997, “Testing of unit roots and other nonstationary 
hypotheses in macroeconomic time series", Journal of Econometrics, 80, 241-268.

Gordon, R.J., 1989. Hysteresis in history. Was there ever a Phillips curve? American Economic Review, Papers and Proceedings, 79, 220-225.

Graafland, J.J., 1991, "On the causes of hysteresis in long term unemployment in the Netherlands", Oxford Bulletin of Economics and Statistics, 53, 2, 155-170.

Granger, C.W.J., 1980, "Long memory relationships and the aggregation of dynamic models", Journal of Econometrics, 14, 227-238.

Granger, C.W.J., 1981, "Some properties of time series data and their use in econometric model specification", Journal of Econometrics, 16, 121-130.

Gregg, P. and A. Manning (1997), "Labour market regulation and unemployment", in D. Snower and G. de la Dehesa (eds.), Unemployment Policy: Government Options for the Labour Market, Cambridge University Press, Cambridge, 395-421.

Hosking, J.R.M., 1981, “Fractional differencing”, Biometrika 68, 168-176.

Im, K.-S., M.H. Pesaran and Y. Shin, 2003, Testing for unit roots in heterogeneous panels, Journal of Econometrics, 115, 53-74.

Im, K.-S., J. Lee and M. Tieslau, 2005, "Panel LM unit root tests with level shifts", Oxford Bulletin of Economics and Statistics, 67, 393-419.

Layard, R., Nickell, S. and R. Jackman (1991), Unemployment: Macroeconomic Performance and the Labour Market, Oxford University Press, Oxford.

Leon-Ledesma, M., 2002, "Unemployment hysteresis in the US states and the EU: A panel approach”, Bulletin of Economic Research, 54, 95-103.

Levin, A., C.-F. Lin and C.-S. Chu, 2002, "Unit root tests in panel data: asymptotic and finite-sample properties", Journal of Econometrics, 108, 1-24.

Lopez, H., E. Ortega and A. Ubide, 1996. Explaining the dynamics of Spanish unemployment, Working Paper in Economics, no.96/14, European University Institute.

Mitchell, W.F., 1993, "Testing for unit roots and persistence in OECD unemployment rates", Applied Economics, 225, 1489-1501.

Murray, C.J. and D.H. Papell, 2000, "Testing for unit roots in panels in the presence of structural change with an application to OECD unemployment", in Nonstationary Panels, Panel Cointegration, and Dynamic Panels (Advances in Econometrics, 15), ed. by B.H. Baltagi, JAI Press, 223-238.

Nickell, S., 1998, "Unemployment: questions and some answers", Economic Journal, 108, 802-816.

Nickell, s. and J. Van Ours, 2000, “The Netherlands and the United Kingdom: a European 
unemployment miracle?", Economic Policy, 30, 135-180.

Nott, L., 1996. Hysteresis in the Canadian labour market. Evidence from the 1990s, Research Report No. 9605, Department of Economics, University of Western Ontario.

OECD (1994), Jobs Study, OECD, Paris.

OECD (1997), Employment Outlook, OECD, Paris.

Papell, D.H., C.J. Murray and H. Ghiblawi, 2000, "The structure of unemployment", Review of Economics and Statistics, 82, 309-315.

Phelps, E.S., 1967, "Phillips curve, expectations of inflation and optimal unemployment", Economica, 34, 254-281.

Phelps, E.S., 1968, "Money-wage dynamics and labor-market equilibrium", Journal of Political Economy, 76, 678-711.

Phelps, E.S., 1994, Structural Slumps: The Modern Equilibrium Theory of Unemployment, Interest, and Assets, Cambridge, MA, Harvard University Press.

Phelps, E.S., 1999, "Behind this structural boom: the role of asset valuations", American Economic Review, Papers and Proceedings, 89, 2, 63-68.

Phillips, P.C.B. and P. Perron, 1988, "Testing for a unit root in a time series regression", Biometrika, 75, 335-346.

Pissarides, C., 1990, Equilibrium Unemployment Theory, Oxford, Basil Blackwell.

Press, W.H., B.P. Flannery, S.A. Teukolsky and W.T. Wetterling, 1986, Numerical recipes: The art of scientific computing, Cambridge University Press, Cambridge.

Robinson, P.M., 1978, "Statistical inference for a random coefficient autoregressive model”, Scandinavian Journal of Statistics, 5, 163-168.

Skalin, J. and T. Teräsvirta (2002), "Modelling asymmetries and moving equilibria in unemployment rates", Macroeconomic Dynamics 6, 202-241.

Song, F.M. and Y. Wu, 1998, "Hysteresis in unemployment? Evidence from OECD countries", Quarterly Review of Economics and Finance, 38, 181-192.

Strazicich, M.C., M. Tieslau and J. Lee, 2001, Hysteresis in unemployment? Evidence from panel unit root tests with structural change, mimeo.

Tschernig, R. and K.F. Zimmermann, 1992. Illusive persitence in German unemployment, Recherches Economiques du Lovaine, 58, 441-453.

Wilkinson, G., 1997. A micro approach to the issue of hysteresis in unemployment; evidence from the 1988-1990 labour market activity survey", Bank of Canada, Working Papers 97-12. 
Zivot, E. and D.W.K. Andrews, 1992, "Further evidence on the Great Crash, the oil-price shock and the unit root hypothesis", Journal of Business and Economic Statistics, 10, 251270. 


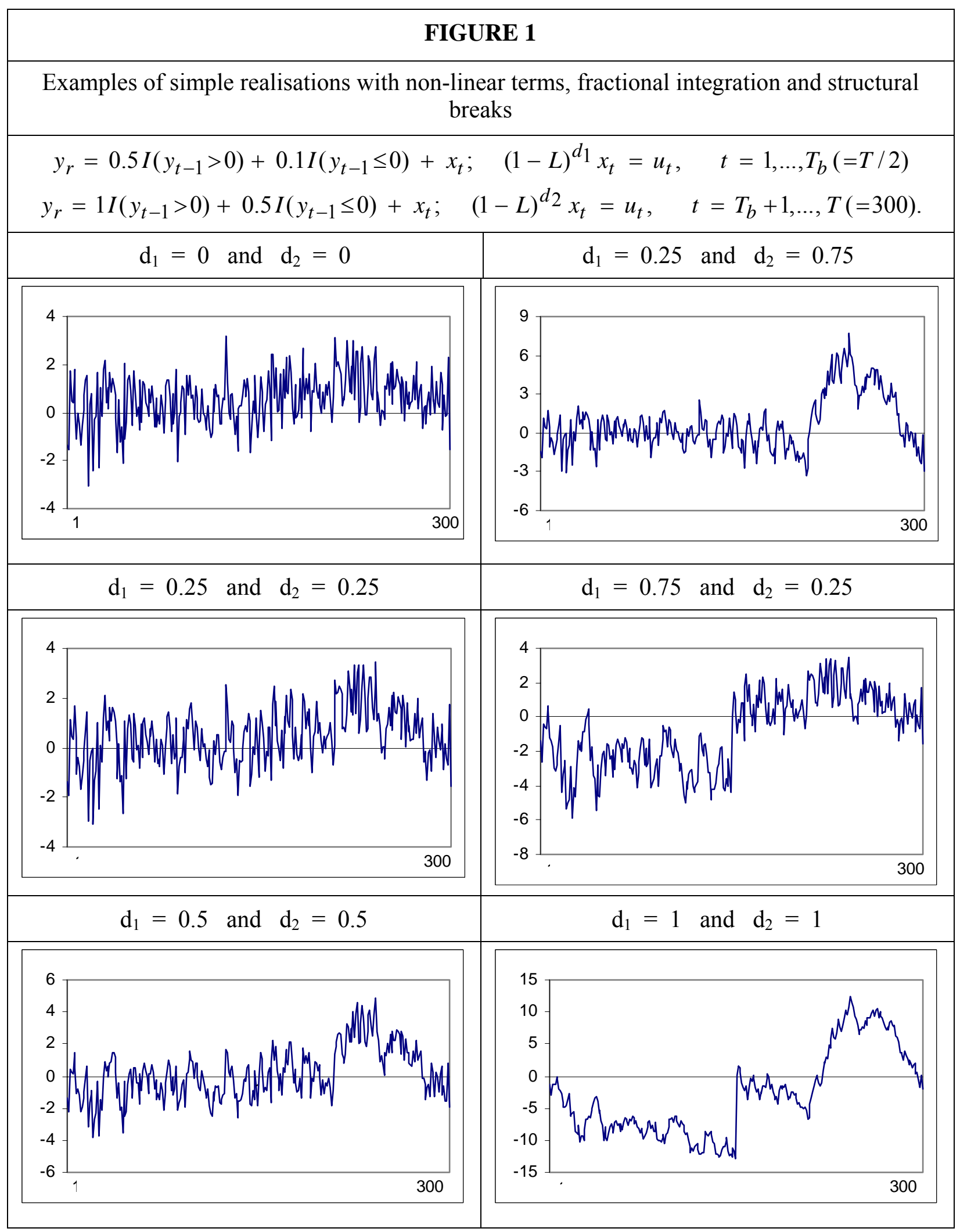




\begin{tabular}{|c|c|c|c|c|c|c|}
\hline \multicolumn{7}{|c|}{ TABLE 1} \\
\hline \multicolumn{7}{|c|}{ Probabilities of detecting the true model with a break at $\mathrm{T} / 2$ and $\mathrm{d}_{1}=0.2$ and $\mathrm{d}_{2}=0.4$} \\
\hline \multicolumn{7}{|c|}{$\begin{array}{c}y_{r}=0.5 I\left(y_{t-1}>0\right)+0.1 I\left(y_{t-1} \leq 0\right)+x_{t} ; \quad(1-L)^{0.2} x_{t}=u_{t}, \quad t=1, \ldots, T_{b}=(T / 2) \\
y_{r}=1 I\left(y_{t-1}>0\right)+0.5 I\left(y_{t-1} \leq 0\right)+x_{t} ; \quad(1-L)^{0.4} x_{t}=u_{t}, \quad t=T_{b}+1, \ldots, T,\end{array}$} \\
\hline $\mathrm{T}^{*}$ & $\mathrm{~d}_{1}$ & $\mathrm{~d}_{2}$ & $\mathrm{~T}=100$ & $\mathrm{~T}=200$ & $\mathrm{~T}=300$ & $\mathrm{~T}=500$ \\
\hline \multirow{2}{*}{$\mathrm{T}_{\mathrm{b}}-2$} & 0.2 & 0.4 & 0.0019 & 0.0019 & 0.0000 & 0.0037 \\
\hline & 0.2 & 0.6 & 0.0019 & 0.0019 & 0.0000 & 0.0018 \\
\hline \multirow{4}{*}{$\mathrm{T}_{\mathrm{b}}-1$} & 0.2 & 0.2 & 0.0099 & 0.0000 & 0.0038 & 0.0000 \\
\hline & 0.2 & 0.4 & 0.0119 & 0.0039 & 0.0174 & 0.0244 \\
\hline & 0.2 & 0.6 & 0.0059 & 0.0115 & 0.0000 & 0.0000 \\
\hline & 0.4 & 0.4 & 0.0019 & 0.0000 & 0.0000 & 0.0000 \\
\hline \multirow{9}{*}{$\mathrm{T}_{\mathrm{b}}$} & 0.2 & 0.2 & 0.3207 & 0.2316 & 0.1356 & 0.0676 \\
\hline & 0.2 & 0.4 & 0.3745 & 0.5791 & 0.7015 & 0.8445 \\
\hline & 0.2 & 0.6 & 0.1235 & 0.0888 & 0.0542 & 0.0261 \\
\hline & 0.2 & 0.8 & 0.0039 & 0.0000 & 0.0000 & 0.0000 \\
\hline & 0.4 & 0.2 & 0.0518 & 0.0094 & 0.0058 & 0.0018 \\
\hline & 0.4 & 0.4 & 0.0418 & 0.0405 & 0.0368 & 0.0150 \\
\hline & 0.4 & 0.6 & 0.0099 & 0.0077 & 0.0019 & 0.0018 \\
\hline & 0.6 & 0.4 & 0.0039 & 0.0000 & 0.0000 & 0.0000 \\
\hline & 0.6 & 0.6 & 0.0019 & 0.0000 & 0.0000 & 0.0000 \\
\hline \multirow{5}{*}{$\mathrm{T}_{\mathrm{b}}+1$} & 0.2 & 0.2 & 0.0159 & 0.0057 & 0.0096 & 0.0018 \\
\hline & 0.2 & 0.4 & 0.0119 & 0.0135 & 0.0251 & 0.0073 \\
\hline & 0.2 & 0.6 & 0.0019 & 0.0039 & 0.0019 & 0.0037 \\
\hline & 0.4 & 0.2 & 0.0019 & 0.0000 & 0.0000 & 0.0000 \\
\hline & 0.4 & 0.4 & 0.0019 & 0.0000 & 0.0019 & 0.0000 \\
\hline $\mathrm{T}_{\mathrm{b}}+2$ & 0.2 & 0.4 & 0.0000 & 0.0000 & 0.0039 & 0.0000 \\
\hline
\end{tabular}

In bold, the probabilities corresponding to the true model. 


\section{TABLE 2}

Probabilities of detecting the true model with a break at $\mathrm{T} / 2$ and $\mathrm{d}_{1}=0.7$ and $\mathrm{d}_{2}=0.3$

$$
\begin{gathered}
y_{r}=0.5 I\left(y_{t-1}>0\right)+0.1 I\left(y_{t-1} \leq 0\right)+x_{t} ; \quad(1-L)^{0.7} x_{t}=u_{t}, \quad t=1, \ldots, T_{b}=(T / 2) \\
y_{r}=1 I\left(y_{t-1}>0\right)+0.5 I\left(y_{t-1} \leq 0\right)+x_{t} ; \quad(1-L)^{0.3} x_{t}=u_{t}, \quad t=T_{b}+1, \ldots, T,
\end{gathered}
$$

\begin{tabular}{|c|c|c|c|c|c|c|}
\hline $\mathrm{T}^{*}$ & $\mathrm{~d}_{1}$ & $\mathrm{~d}_{2}$ & $\mathrm{~T}=100$ & $\mathrm{~T}=200$ & $\mathrm{~T}=300$ & $\mathrm{~T}=500$ \\
\hline \multirow{9}{*}{$\mathrm{T}_{\mathrm{b}}-2$} & 0.3 & 0.1 & 0.0036 & 0.0000 & 0.0000 & 0.0000 \\
\hline & 0.3 & 0.3 & 0.0019 & 0.0000 & 0.0000 & 0.0000 \\
\hline & 0.5 & 0.1 & 0.0036 & 0.0000 & 0.0000 & 0.0000 \\
\hline & 0.5 & 0.3 & 0.0036 & 0.0093 & 0.0015 & 0.0013 \\
\hline & 0.7 & 0.1 & 0.0055 & 0.0062 & 0.0015 & 0.0013 \\
\hline & 0.7 & 0.3 & 0.0055 & 0.0139 & 0.0185 & 0.0215 \\
\hline & 0.7 & 0.5 & 0.0018 & 0.0015 & 0.0015 & 0.0000 \\
\hline & 0.9 & 0.1 & 0.0018 & 0.0000 & 0.0000 & 0.0000 \\
\hline & 0.9 & 0.3 & 0.0036 & 0.0000 & 0.0000 & 0.0000 \\
\hline \multirow{7}{*}{$\mathrm{T}_{\mathrm{b}}-1$} & 0.3 & 0.3 & 0.0019 & 0.0015 & 0.0000 & 0.0000 \\
\hline & 0.5 & 0.1 & 0.0092 & 0.0015 & 0.0000 & 0.0000 \\
\hline & 0.5 & 0.3 & 0.0055 & 0.0062 & 0.0061 & 0.0013 \\
\hline & 0.7 & 0.1 & 0.0092 & 0.0030 & 0.0030 & 0.0026 \\
\hline & 0.7 & 0.3 & 0.0147 & 0.0170 & 0.0231 & 0.0269 \\
\hline & 0.7 & 0.5 & 0.0018 & 0.0000 & 0.0015 & 0.0013 \\
\hline & 0.9 & 0.3 & 0.0036 & 0.0015 & 0.0000 & 0.0000 \\
\hline \multirow{13}{*}{$\mathrm{T}_{\mathrm{b}}$} & 0.1 & 0.3 & 0.0036 & 0.0000 & 0.0000 & 0.0000 \\
\hline & 0.3 & 0.1 & 0.0220 & 0.0019 & 0.0000 & 0.0000 \\
\hline & 0.3 & 0.3 & 0.073 & 0.0000 & 0.0000 & 0.0000 \\
\hline & 0.3 & 0.5 & 0.036 & 0.0000 & 0.0000 & 0.0000 \\
\hline & 0.5 & 0.1 & 0.0662 & 0.0481 & 0.0169 & 0.0081 \\
\hline & 0.5 & 0.3 & 0.1104 & 0.0729 & 0.0601 & 0.0377 \\
\hline & 0.5 & 0.5 & 0.0313 & 0.0124 & 0.0030 & 0.0000 \\
\hline & 0.7 & 0.1 & 0.1694 & 0.1770 & 0.1203 & 0.0661 \\
\hline & 0.7 & 0.3 & 0.1915 & 0.3742 & 0.5540 & 0.7125 \\
\hline & 0.7 & 0.5 & 0.0497 & 0.0465 & 0.0354 & 0.0148 \\
\hline & 0.9 & 0.1 & 0.0773 & 0.0326 & 0.01008 & 0.0026 \\
\hline & 0.9 & 0.3 & 0.0681 & 0.0652 & 0.0478 & 0.0229 \\
\hline & 0.9 & 0.5 & 0.0202 & 0.0077 & 0.0092 & 0.0013 \\
\hline \multirow{8}{*}{$\mathrm{T}_{\mathrm{b}}+1$} & 0.5 & 0.1 & 0.0019 & 0.0046 & 0.0015 & 0.0000 \\
\hline & 0.5 & 0.3 & 0.0147 & 0.0015 & 0.0060 & 0.0039 \\
\hline & 0.5 & 0.5 & 0.0019 & 0.0015 & 0.0000 & 0.0000 \\
\hline & 0.7 & 0.1 & 0.0239 & 0.0046 & 0.0169 & 0.0107 \\
\hline & 0.7 & 0.3 & 0.0184 & 0.0496 & 0.0447 & 0.0553 \\
\hline & 0.7 & 0.5 & 0.0092 & 0.0093 & 0.0092 & 0.0013 \\
\hline & 0.9 & 0.1 & 0.0165 & 0.0030 & 0.0015 & 0.0000 \\
\hline & 0.9 & 0.3 & 0.0073 & 0.0061 & 0.0045 & 0.0054 \\
\hline \multirow{2}{*}{$\mathrm{T}_{\mathrm{b}}+2$} & 0.5 & 0.5 & 0.0019 & 0.0031 & 0.0000 & 0.0000 \\
\hline & 0.7 & 0.1 & 0.0055 & 0.0155 & 0.0000 & 0.0000 \\
\hline
\end{tabular}

In bold, the probabilities corresponding to the true model. 
TABLE 3

Probabilities of detecting the true model with a break at $\mathrm{T} / 4$ and $\mathrm{d}_{1}=0.6$ and $\mathrm{d}_{2}=0.8$

$$
\begin{gathered}
y_{r}=0.5 I\left(y_{t-1}>0\right)+0.1 I\left(y_{t-1} \leq 0\right)+x_{t} ; \quad(1-L)^{0.6} x_{t}=u_{t}, \quad t=1, \ldots, T_{b}=(T / 4) \\
y_{r}=1 I\left(y_{t-1}>0\right)+0.5 I\left(y_{t-1} \leq 0\right)+x_{t} ; \quad(1-L)^{0.8} x_{t}=u_{t}, \quad t=T_{b}+1, \ldots, T,
\end{gathered}
$$

\begin{tabular}{|c|c|c|c|c|c|c|}
\hline $\mathrm{T}^{*}$ & $\mathrm{~d}_{1}$ & $\mathrm{~d}_{2}$ & $\mathrm{~T}=100$ & $\mathrm{~T}=200$ & $\mathrm{~T}=300$ & $\mathrm{~T}=500$ \\
\hline \multirow{6}{*}{$\mathrm{T}_{\mathrm{b}}-2$} & 0.4 & 0.6 & 0.0044 & 0.0000 & 0.0000 & 0.0000 \\
\hline & 0.4 & 0.8 & 0.0088 & 0.0079 & 0.0075 & 0.0051 \\
\hline & 0.4 & 1.0 & 0.0044 & 0.0000 & 0.0000 & 0.0000 \\
\hline & 0.6 & 0.8 & 0.0021 & 0.0177 & 0.0132 & 0.0323 \\
\hline & 0.8 & 0.6 & 0.0021 & 0.0000 & 0.0000 & 0.0000 \\
\hline & 0.8 & 0.8 & 0.0044 & 0.0059 & 0.0075 & 0.0034 \\
\hline \multirow{6}{*}{$\mathrm{T}_{\mathrm{b}}-1$} & 0.4 & 0.6 & 0.0088 & 0.0000 & 0.0000 & 0.0000 \\
\hline & 0.4 & 0.8 & 0.0154 & 0.0177 & 0.0150 & 0.0034 \\
\hline & 0.6 & 0.6 & 0.0088 & 0.0019 & 0.0000 & 0.0000 \\
\hline & 0.6 & 0.8 & 0.0022 & 0.0197 & 0.0189 & 0.0357 \\
\hline & 0.8 & 0.6 & 0.0088 & 0.0019 & 0.0018 & 0.0017 \\
\hline & 0.8 & 0.8 & 0.0022 & 0.000 & 0.0113 & 0.0017 \\
\hline \multirow{13}{*}{$\mathrm{T}_{\mathrm{b}}$} & 0.4 & 0.6 & 0.0927 & 0.0256 & 0.0189 & 0.0034 \\
\hline & 0.4 & 0.8 & 0.2980 & 0.2984 & 0.1988 & 0.1499 \\
\hline & 0.4 & 1.0 & 0.0794 & 0.0256 & 0.0056 & 0.0017 \\
\hline & 0.6 & 0.6 & 0.0463 & 0.0494 & 0.0284 & 0.0051 \\
\hline & 0.6 & 0.8 & 0.1346 & 0.3379 & 0.4659 & 0.5928 \\
\hline & 0.6 & 1.0 & 0.0463 & 0.0276 & 0.0113 & 0.0034 \\
\hline & 0.8 & 0.4 & 0.0066 & 0.0000 & 0.0000 & 0.0000 \\
\hline & 0.8 & 0.6 & 0.0198 & 0.0079 & 0.0037 & 0.0000 \\
\hline & 0.8 & 0.8 & 0.0684 & 0.0869 & 0.0928 & 0.0562 \\
\hline & 0.8 & 1.0 & 0.0198 & 0.0118 & 0.0075 & 0.0000 \\
\hline & 1.0 & 0.6 & 0.0110 & 0.0000 & 0.0000 & 0.0000 \\
\hline & 1.0 & 0.8 & 0.0286 & 0.0019 & 0.0000 & 0.0000 \\
\hline & 1.0 & 1.0 & 0.0088 & 0.0000 & 0.0000 & 0.0000 \\
\hline \multirow{7}{*}{$\mathrm{T}_{\mathrm{b}}+1$} & 0.4 & 0.6 & 0.0066 & 0.0000 & 0.000 & 0.0000 \\
\hline & 0.4 & 0.8 & 0.0088 & 0.0059 & 0.0056 & 0.0034 \\
\hline & 0.6 & 0.6 & 0.0088 & 0.0039 & 0.0000 & 0.0000 \\
\hline & 0.6 & 0.8 & 0.0022 & 0.0197 & 0.0340 & 0.0579 \\
\hline & 0.8 & 0.6 & 0.0176 & 0.0000 & 0.0000 & 0.0000 \\
\hline & 0.8 & 0.8 & 0.0066 & 0.0079 & 0.0208 & 0.0102 \\
\hline & 1.0 & 0.6 & 0.0044 & 0.0000 & 0.0018 & 0.0000 \\
\hline \multirow{4}{*}{$\mathrm{T}_{\mathrm{b}}+2$} & 0.6 & 0.6 & 0.0044 & 0.0039 & 0.0000 & 0.0000 \\
\hline & 0.6 & 0.8 & 0.0021 & 0.0059 & 0.0189 & 0.0255 \\
\hline & 0.6 & 1.0 & 0.0000 & 0.0039 & 0.0000 & 0.0017 \\
\hline & 0.8 & 0.8 & 0.0044 & 0.0019 & 0.0094 & 0.0052 \\
\hline
\end{tabular}

In bold, the probabilities corresponding to the true model. 
TABLE 4

\begin{tabular}{|c|c|c|c|c|c|c|c|c|c|c|}
\hline \multicolumn{11}{|c|}{ Results for the UNITED STATES } \\
\hline & \multicolumn{2}{|c|}{ Model 1} & \multicolumn{2}{|c|}{ Model 2} & \multicolumn{2}{|c|}{ Model 3} & \multicolumn{2}{|c|}{ Model 4} & \multicolumn{2}{|c|}{ Model 5} \\
\hline & W. N. & $\mathrm{AR}(1)$ & W. N. & $\mathrm{AR}(1)$ & W. N. & $\mathrm{AR}(1)$ & W. N. & $\operatorname{AR}(1)$ & W. N. & $\mathrm{AR}(1)$ \\
\hline $\mathrm{T}_{\mathrm{b}}$ & $73 \mathrm{Q} 4$ & $75 \mathrm{Q} 1$ & 75Q1 & $74 \mathrm{Q} 4$ & $75 \mathrm{Q} 1$ & 75Q1 & $72 \mathrm{Q} 2$ & 74Q3 & 74Q4 & 74Q3 \\
\hline $\mathrm{d}_{1}$ & 0.88 & 0.92 & 0.68 & 0.71 & 0.67 & 0.72 & 0.72 & 1.01 & 0.74 & 0.66 \\
\hline $\mathrm{d}_{2}$ & 0.96 & 0.92 & 0.83 & 1.03 & 0.80 & 1.11 & 0.96 & 0.86 & 0.86 & 1.03 \\
\hline$\alpha_{1}$ & --- & --- & $\begin{array}{l}5.758 \\
(10.48)\end{array}$ & $\begin{array}{c}4.994 \\
(4.36)\end{array}$ & $\begin{array}{c}5.799 \\
(10.16)\end{array}$ & \begin{tabular}{|c|}
4.887 \\
$(3.36)$
\end{tabular} & --- & --- & --- & --- \\
\hline$\alpha_{2}$ & -- & -- & $\begin{array}{l}\mathbf{8 . 8 3 7} \\
(15.42) \\
\end{array}$ & \begin{tabular}{|c}
16.349 \\
$(8.31)$ \\
\end{tabular} & \begin{tabular}{|c}
10.701 \\
$(6.86)$ \\
\end{tabular} & \begin{tabular}{|c}
10.948 \\
$(2.82)$ \\
\end{tabular} & --- & --- & -- & --- \\
\hline$\beta_{1}$ & --- & --- & --- & --- & $\begin{array}{r}-0.007 \\
(-0.27) \\
\end{array}$ & $\begin{array}{c}0.0052 \\
(0.16)\end{array}$ & --- & --- & --- & --- \\
\hline$\beta_{2}$ & --- & --- & --- & --- & $\begin{array}{r}-0.003 \\
(-1.32) \\
\end{array}$ & \begin{tabular}{|c}
-0.038 \\
$(-0.68)$ \\
\end{tabular} & --- & --- & --- & --- \\
\hline$\gamma_{1}^{1}$ & --- & --- & --- & --- & --- & --- & $\begin{array}{l}5.342 \\
(8.93)\end{array}$ & $\begin{array}{l}0.503 \\
(1.03)\end{array}$ & --- & --- \\
\hline$\gamma_{1}^{2}$ & --- & --- & --- & --- & --- & --- & $\begin{array}{l}0.350 \\
(1.18)\end{array}$ & $\begin{array}{l}0.363 \\
(1.47)\end{array}$ & --- & --- \\
\hline$\gamma_{2}^{1}$ & --- & --- & --- & --- & --- & --- & $\begin{array}{l}5.419 \\
(9.30)\end{array}$ & $\begin{array}{l}0.606 \\
(1.27)\end{array}$ & --- & --- \\
\hline$\gamma_{2}^{2}$ & --- & --- & --- & --- & --- & --- & $\begin{array}{c}0.598 \\
(2.09) \\
\end{array}$ & $\begin{array}{l}0.601 \\
(2.51) \\
\end{array}$ & --- & --- \\
\hline$\delta_{1}^{1}$ & --- & --- & --- & --- & --- & --- & --- & --- & $\begin{array}{c}-0.609 \\
(-1.07) \\
\end{array}$ & $\begin{array}{c}-0.536 \\
(-0.43) \\
\end{array}$ \\
\hline$\delta_{1}^{2}$ & --- & --- & --- & --- & --- & --- & --- & --- & $\begin{array}{c}2.973 \\
(5.17)\end{array}$ & $\begin{array}{c}11.485 \\
(5.26)\end{array}$ \\
\hline$\delta_{2}^{1}$ & --- & --- & --- & --- & --- & --- & --- & --- & $\begin{array}{c}-0.327 \\
(-0.56)\end{array}$ & $\begin{array}{c}-0.234 \\
(-0.19)\end{array}$ \\
\hline$\delta_{2}^{2}$ & --- & --- & --- & --- & --- & --- & --- & --- & $\begin{array}{l}3.123 \\
(5.29)\end{array}$ & $\begin{array}{c}11.501 \\
(5.20) \\
\end{array}$ \\
\hline$\tau_{1}$ & --- & -0.162 & --- & -0.053 & --- & -0.044 & --- & -0.095 & --- & 0.100 \\
\hline$\tau_{2}$ & --- & -0.111 & --- & -0.316 & --- & -0.418 & --- & -0.002 & --- & -0.291 \\
\hline
\end{tabular}

t-values in parentheses. In bold, significant coefficients at the $95 \%$ significance level. 
TABLE 5

\section{Results for the UNITED KINGDOM}

\begin{tabular}{|c|c|c|c|c|c|c|c|c|c|c|}
\hline & \multicolumn{2}{|c|}{ Model 1} & \multicolumn{2}{|c|}{ Model 2} & \multicolumn{2}{|c|}{ Model 3} & \multicolumn{2}{|c|}{ Model 4} & \multicolumn{2}{|c|}{ Model 5} \\
\hline & W. N. & $\operatorname{AR}(1)$ & W. N. & $\mathrm{AR}(1)$ & W. N. & $\mathrm{AR}(1)$ & W. N. & $\operatorname{AR}(1)$ & W. N. & $\operatorname{AR}(1)$ \\
\hline $\mathrm{T}_{\mathrm{b}}$ & $73 \mathrm{~m} 11$ & $73 \mathrm{~m} 11$ & $83 \mathrm{ml}$ & $81 \mathrm{~m} 4$ & $83 \mathrm{~m} 1$ & $81 \mathrm{~m} 1$ & $73 \mathrm{~m} 9$ & $80 \mathrm{~m} 3$ & $82 \mathrm{~m} 12$ & $81 \mathrm{~m} 3$ \\
\hline $\mathrm{d}_{1}$ & 1.03 & 1.03 & 1.53 & 1.82 & 1.52 & 1.84 & 0.99 & 1.50 & 1.52 & 1.83 \\
\hline $\mathrm{d}_{2}$ & 1.18 & 1.17 & 1.37 & 1.52 & 1.37 & 1.52 & 1.19 & 1.47 & 1.37 & 1.52 \\
\hline$\alpha_{1}$ & --- & -- & $\begin{array}{c}3.754 \\
(70.42)\end{array}$ & \begin{tabular}{|l|}
3.615 \\
$(38.11)$ \\
\end{tabular} & \begin{tabular}{|l|}
3.725 \\
$(65.34)$ \\
\end{tabular} & \begin{tabular}{|c|}
3.681 \\
$(28.28)$ \\
\end{tabular} & --- & --- & --- & --- \\
\hline$\alpha_{2}$ & --- & --- & $\begin{array}{l}11.293 \\
(151.7)\end{array}$ & \begin{tabular}{|l|}
9.236 \\
$(46.34)$ \\
\end{tabular} & \begin{tabular}{|c}
12.761 \\
$(2.94)$ \\
\end{tabular} & \begin{tabular}{|c}
16.696 \\
$(2.30)$ \\
\end{tabular} & --- & --- & --- & -- \\
\hline$\beta_{1}$ & --- & --- & --- & -- & $\begin{array}{l}0.058 \\
(1.38)\end{array}$ & $\begin{array}{l}0.069 \\
(0.66) \\
\end{array}$ & --- & --- & --- & --- \\
\hline$\beta_{2}$ & --- & --- & --- & --- & $\begin{array}{c}-0.010 \\
(-0.34) \\
\end{array}$ & $\begin{array}{c}-0.073 \\
(-1.18) \\
\end{array}$ & --- & --- & --- & --- \\
\hline$\gamma_{1}^{1}$ & --- & --- & --- & --- & -- & -- & $\begin{array}{c}0.479 \\
(2.04)\end{array}$ & $\begin{array}{c}-0.008 \\
(-0.56) \\
\end{array}$ & --- & --- \\
\hline$\gamma_{1}^{2}$ & --- & --- & --- & --- & --- & --- & $\begin{array}{l}0.035 \\
(0.20)\end{array}$ & $\begin{array}{l}0.015 \\
(1.12)\end{array}$ & --- & --- \\
\hline$\gamma_{2}^{1}$ & --- & --- & --- & --- & --- & --- & $\begin{array}{c}-0.005 \\
(-0.02)\end{array}$ & $\begin{array}{c}-0.084 \\
(-0.03)\end{array}$ & --- & --- \\
\hline$\gamma_{2}^{2}$ & --- & --- & -- & --- & --- & --- & $\begin{array}{l}0.041 \\
(2.38)\end{array}$ & $\begin{array}{l}0.054 \\
(0.55)\end{array}$ & --- & --- \\
\hline$\delta_{1}^{1}$ & --- & --- & --- & --- & --- & --- & --- & -- & $\begin{array}{l}-3.386 \\
(-44.80\end{array}$ & $\begin{array}{c}-3.528 \\
(-33.43) \\
\end{array}$ \\
\hline$\delta_{1}^{2}$ & --- & -- & --- & --- & --- & -- & --- & --- & $\begin{array}{l}4.031 \\
(3.21)\end{array}$ & $\begin{array}{l}1.974 \\
(9.92)\end{array}$ \\
\hline$\delta_{2}^{1}$ & --- & --- & --- & --- & --- & --- & --- & --- & $\begin{array}{l}-3.406 \\
(-63.76)\end{array}$ & $\begin{array}{c}-3.535 \\
(-3.76)\end{array}$ \\
\hline$\delta_{2}^{2}$ & --- & -- & --- & --- & --- & -- & --- & --- & $\begin{array}{l}4.024 \\
(3.11)\end{array}$ & $\begin{array}{l}1.966 \\
(9.77)\end{array}$ \\
\hline$\tau_{1}$ & --- & 0.035 & --- & -0.513 & --- & -0.527 & --- & 0.016 & --- & -0.520 \\
\hline$\tau_{2}$ & --- & -0.107 & --- & -0.271 & --- & -0.260 & --- & -0.032 & --- & -0.271 \\
\hline
\end{tabular}

t-values in parentheses. In bold, significant coefficients at the $95 \%$ significance level. 
TABLE 6

\section{Results for JAPAN}

\begin{tabular}{|c|c|c|c|c|c|c|c|c|c|c|}
\hline & \multicolumn{2}{|c|}{ Model 1} & \multicolumn{2}{|c|}{ Model 2} & \multicolumn{2}{|c|}{ Model 3} & \multicolumn{2}{|c|}{ Model 4} & \multicolumn{2}{|c|}{ Model 5} \\
\hline & W. N. & $\operatorname{AR}(1)$ & W. N. & $\operatorname{AR}(1)$ & W. N. & $\mathrm{AR}(1)$ & W. N. & $\operatorname{AR}(1)$ & W. N. & $\operatorname{AR}(1)$ \\
\hline $\mathrm{T}_{\mathrm{b}}$ & 93Q1 & 92Q4 & 93Q2 & 93Q1 & $93 \mathrm{Q} 2$ & 93Q1 & 92Q3 & 92Q2 & 93Q1 & 92Q4 \\
\hline $\mathrm{d}_{1}$ & 1.07 & 1.06 & 0.93 & 0.04 & 0.95 & 0.03 & 1.02 & 1.16 & 0.93 & 0.14 \\
\hline $\mathrm{d}_{2}$ & 1.11 & 1.16 & 1.42 & 1.00 & 1.40 & 1.00 & 1.16 & 1.17 & 1.45 & 1.00 \\
\hline$\alpha_{1}$ & --- & --- & $\begin{array}{l}1.2711 \\
(4.75)\end{array}$ & $\begin{array}{c}2.701 \\
(6.47)\end{array}$ & $\begin{array}{c}1.283 \\
(4.78)\end{array}$ & $\begin{array}{l}3.428 \\
(4.03)\end{array}$ & --- & --- & --- & --- \\
\hline$\alpha_{2}$ & --- & --- & $\begin{array}{l}2.3925 \\
(22.19)\end{array}$ & $\begin{array}{c}-151.66 \\
(* * *)\end{array}$ & $\begin{array}{l}-1.568 \\
(-0.29)\end{array}$ & $\begin{array}{l}-47.710 \\
(-18.10)\end{array}$ & --- & --- & --- & --- \\
\hline$\beta_{1}$ & --- & --- & --- & --- & $\begin{array}{l}-0.020 \\
(-0.49)\end{array}$ & $\begin{array}{l}-0.013 \\
(-1.08)\end{array}$ & --- & --- & --- & --- \\
\hline$\beta_{2}$ & --- & --- & --- & --- & $\begin{array}{l}0.048 \\
(0.75) \\
\end{array}$ & $\begin{array}{l}0.046 \\
(2.30) \\
\end{array}$ & --- & --- & --- & --- \\
\hline$\gamma_{1}^{1}$ & --- & --- & --- & --- & --- & --- & $\begin{array}{l}0.276 \\
(3.94)\end{array}$ & $\begin{array}{l}0.032 \\
(0.65)\end{array}$ & --- & --- \\
\hline$\gamma_{1}^{2}$ & --- & --- & --- & --- & --- & --- & $\begin{array}{l}-0.146 \\
(-0.74)\end{array}$ & $\begin{array}{c}-0.361 \\
(-1.65)\end{array}$ & --- & --- \\
\hline$\gamma_{2}^{1}$ & --- & --- & --- & --- & --- & --- & $\begin{array}{c}0.246 \\
(3.56)\end{array}$ & $\begin{array}{c}0.008 \\
(0.17)\end{array}$ & --- & --- \\
\hline$\gamma_{2}^{2}$ & --- & --- & --- & --- & --- & --- & $\begin{array}{c}-0.016 \\
(-0.08)\end{array}$ & $\begin{array}{r}-0.413 \\
(-1.71) \\
\end{array}$ & --- & --- \\
\hline$\delta_{1}^{1}$ & --- & --- & --- & --- & --- & --- & --- & --- & $\begin{array}{l}-1.432 \\
(-4.34)\end{array}$ & $\begin{array}{c}-0.211 \\
(-0.81)\end{array}$ \\
\hline$\delta_{1}^{2}$ & --- & --- & --- & --- & --- & --- & --- & --- & $\begin{array}{l}-0.624 \\
(-4.25)\end{array}$ & $\begin{array}{l}-153.25 \\
(-18.60)\end{array}$ \\
\hline$\delta_{2}^{1}$ & --- & --- & --- & --- & --- & --- & --- & --- & $\begin{array}{l}-1.513 \\
(-5.66)\end{array}$ & $\begin{array}{c}-0.275 \\
(-1.09)\end{array}$ \\
\hline$\delta_{2}^{2}$ & --- & --- & --- & --- & --- & --- & --- & --- & $\begin{array}{r}-0.479 \\
(-4.64)\end{array}$ & $\begin{array}{r}-153.19 \\
(-18.59)\end{array}$ \\
\hline$\tau_{1}$ & --- & 0.038 & --- & 0.969 & --- & 0.956 & --- & -0.378 & --- & 0.925 \\
\hline$\tau_{2}$ & --- & -0.793 & --- & 0.016 & --- & 0.054 & --- & -0.704 & --- & 0.016 \\
\hline
\end{tabular}

t-values in parentheses. In bold, significant coefficients at the $95 \%$ significance level. 


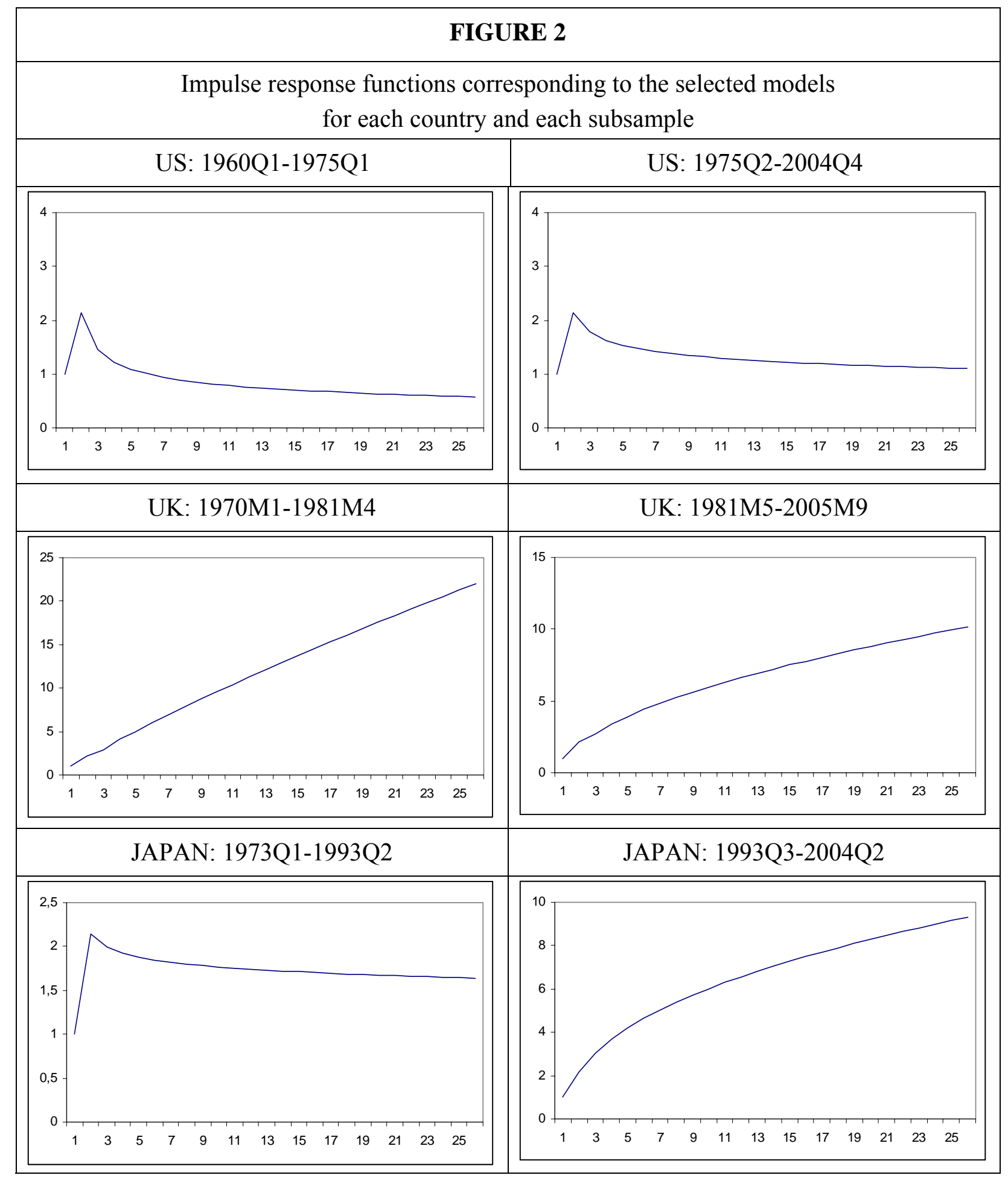

